\title{
Los migrantes agrícolas "temporales" en Saint-Rémi, Quebec: representaciones sociales desde la óptica de sus habitantes
}

\author{
Aarón Díaz Mendiburo*
}

\section{RESUMEN}

A través de la teoría de las representaciones sociales propuesta por Sergei Moscovici (1979) y del empleo del trabajo etnográfico, explico en este artículo cuáles son las representaciones que tienen los inmigrantes, principalmente latinoamericanos, y aquellos nacidos en Quebec residentes en Saint-Rémi, tanto en el espacio urbano como en el rural, respecto de los trabajadores agrícolas "temporales", y cómo dichas representaciones (en su mayoría negativas) impactan en el trato que se les da a los jornaleros mexicanos y guatemaltecos.

Palabras clave: migración "temporal", representaciones sociales, relaciones interculturales, Quebec.

\begin{abstract}
Using the theory of social representations proposed by Sergei Moscovici (1979) and ethnographic work, this article explains the representations of "temporary" agricultural workers held by immigrants -mainly Latin Americans- and Quebec-born residents in Saint-Rémi both in urban and rural areas. The author also delves into how those representations -mostly negative- impact the treatment of Mexican and Guatemalan day-workers.
\end{abstract}

Key words: "temporary" migration, social representations, inter-cultural relations, Quebec.

\footnotetext{
* Profesor en la Escuela de Trabajo Social de la Universidad Autónoma del Estado de Morelos, <faraondiaz@ yahoo.com.mx>. El trabajo de campo se realizó gracias al financiamiento de Conacyt, la unAm y el Instituto de Investigaciones Antropológicas (IIA), así como al Emerging Leaders in the Americas Program (ELAP), al apoyo de la Universidad de Montreal, a través de la Cátedra de Estudios sobre México Contemporáneo (CEMC), dirigida en su momento por Patricia Martin, bajo la supervisión y retroalimentación de Jorge Pantaleón, actual director de la cEMc. Asimismo, recibió el apoyo de la Universidad de Guelph, Universidad Wilfrid Laurier, vía el International Migration Research Centre (IMRC) y de las doctoras Cristina Oehmichen, Kerry Preibisch, Sara María Lara, Jenna Hennebry, Janet McLaughlin y los doctores Gilberto Giménez y Alfredo Guerrero.
} 
Adiós, adiós mi amante tengo que abandonarte ellos no se merecen esta acción de mi parte

Adiós, adiós mi amante aunque he llegado a amarte es mi deber de padre el que me obliga a dejarte adiós, adiós mi amante...

"Adiós a mi amante" Montez de Durango

El epígrafe es un fragmento de la canción que escuché el 23 de septiembre de 2007 al llegar a "La molisana", un café-bar-discoteca ubicado en la calle principal de Leamington, ciudad del sur de Ontario, Canadá. Dicho lugar recibe, año tras año, a miles de hombres y cientos de mujeres caribeñas y mexicanas, de entre otras nacionalidades, para trabajar fundamentalmente en la agricultura. El número de hombres y mujeres mexicanos que acuden a Leamington y a otras comunidades canadienses se ha incrementado considerablemente en la última década. De acuerdo con la Dirección de Movilidad Laboral de la Secretaría del Trabajo y Previsión Social (styps), en el año 2000 llegaron a Canadá un total de 9175 migrantes y en 2010, 15809 de éstos, 621 eran mujeres, las cuales son madres solteras, salvo algunas excepciones, ya que es un requisito establecido por la STyPs para ser reclutadas. Esta medida, por un lado, se interpretaría como una forma de apoyo a las madres solteras, o bien, como una manera de asegurar que el lazo afectivo que tienen con sus hijos sirva de control para evitar que deserten del programa y se queden en Canadá como indocumentadas. Mientras las mujeres permanecen fuera de México, el cuidado de sus hijos está a cargo de sus redes familiares.

Los jornaleros y jornaleras migran a Canadá a través de un acuerdo que México firmó en 1973 llamado Programa de Trabajadores Agrícolas Temporales (PTAT) o Programme des Travailleurs Agricoles Saisonniers (PTAS), como se denomina en francés, o Seasonal Agricultural Worker Program (SAWP), ${ }^{1}$ como se lo conoce en inglés.

\footnotetext{
1 Administrativamente hablando, el PTAT es un acuerdo entre Canadá y varios países que se caracteriza por enviar hombres y mujeres a laborar en los campos de cultivo y empacadoras canadienses de dos a ocho meses por año. Actualmente el programa funciona en nueve de las diez provincias, con excepción de Terranova y Labrador y, en 2013, se incorporó uno de los tres territorios, el de Yukón. Ontario es la provincia con mayor cantidad de campos de cultivo y más necesidad de mano de obra extranjera, anualmente capta un 70 por ciento de los migrantes jornaleros, seguida por Columbia Británica y Quebec. Desde 2005, todos los estados de la república mexicana han enviado personal para trabajar en Canadá, aunque la mayor concentración proviene del Estado de México, Tlaxcala, Puebla, Guanajuato, Morelos e Hidalgo. A partir de 2002,
} 
A “La molisana" van los canadienses todos los días, pero sólo unos cuantos asisten los sábados. Uno de ellos es un granjero asiduo al lugar, que siempre llega acompañado de un familiar o amigo, el resto son mujeres que acuden para bailar o entablar algún vínculo más íntimo con los hombres mexicanos. Los sábados son los días de "los mexicanos" y el lugar se convierte en uno de los pocos espacios en que los trabajadores agrícolas pueden relajarse momentáneamente de lo que significa ser un trabajador "temporal" 2 cautivo $^{3}$ en un país completamente ajeno al suyo. Asisten centenares de hombres y unas cuantas mujeres -reflejo de su bajo porcentaje dentro del PTAT, sólo el 3 por ciento- a beber, comer, bailar, platicar, seducir, es decir, a tener vida social. En "La molisana", ellas se concentran alrededor de la pista de baile en donde tienen una amplia posibilidad de decidir con quién bailar, debido a que la mayoría de los concurrentes son hombres. Mientras observaba esa situación y también las pequeñas banderas mexicanas que decoraban el lugar, otra escena llamó mi atención: dos hombres bailaban juntos al ritmo de los acordes emitidos por el grupo de música que estaba integrado por migrantes agrícolas; ellos expresaban, sin inhibiciones, su camaradería, se abrazaban, se tocaban, bebían y demostraban sus afectos como suelen hacerlo otros hombres en cualquier celebración pública o privada que se lleve a cabo en México. Un tercero llegó para unirse y continuar con el ritual, se empujaban, cantaban, sonreían y se decían cosas en voz alta:-Amigo, salucita, vengase pa'ca, éste es mi cuate. Repen-

llegan a Canadá hombres y mujeres bajo otro modo de contratación conocido en español como Proyecto piloto (nombre que utilizaré a lo largo de este trabajo); en francés y en inglés se renombraron en 2007 como "Project pilote à l'intention de travailleurs possédant un niveau réduit de formation officielle" y "Pilot project for workers with lower levels of formal training", respectivamente. El proyecto piloto se creó como una respuesta del gobierno canadiense a la falta de mano de obra que impulsara el crecimiento de su economía. El objetivo principal es permitir la importación de trabajadores de cualquier parte del mundo para desempeñar labores que comprendan los niveles de habilidades c y D establecidas en la Clasificación Nacional de Ocupaciones (National Occupational Classificacation, NOC). La habilidad c comprende las actividades que requieren de uno a cuatro años de educación secundaria o hasta dos años de capacitación para el trabajo o experiencia laboral específica, mientras que la D requiere poca experiencia laboral y no es necesario ningún requisito de educación formal.

2 Entrecomillo la palabra "temporal" debido a que esta supuesta temporalidad a la que se refiere el Ministerio de Empleo y Desarrollo Social de Canadá (Employment and Social Development Canada) es arbitraria. En la descripción que hace en su página web respecto del Seasonal Agricultural Worker Program (SAWP), menciona que este programa permite a los empleadores contratar a los trabajadores temporalmente en un periodo no mayor a ocho meses ( $\mathrm{del} 1^{\circ}$ de enero al 15 de diciembre, y no menor a 240 horas en un periodo de seis semanas o menos), es decir, que según los parámetros anteriores, incluso aquellos trabajadores que viven el mayor tiempo del año en Canadá siguen siendo temporales. De acuerdo con estadísticas de 2012 de la Dirección de Movilidad Laboral de la Secretaría del Trabajo y Previsión Social (styps), el 64.98 por ciento de los trabajadores agrícolas permanecen de seis a ocho meses en Canadá, es decir, más tiempo que en su país. Si a esto agregamos que el 75 por ciento de los jornaleros en 2010 tenían por lo menos cuatro años de participar en el programa, el 57 por ciento seis o más y el 22 por ciento más de diez años (Hennebry, 2012: 13), entonces el adjetivo "temporal" no sería el correcto para aplicarlo a la mayoría de los jornaleros, pues sólo el 35.02 por ciento pasa más tiempo en México que en Canadá.

${ }^{3}$ Utilizo el término como la imposibilidad de los trabajadores para cambiar de trabajo y debido a la plena disposición para brindar su mano de obra cuando se les requiera (Basok, 2002: 14). 
tinamente, uno de los empleados los tomó de los brazos a la fuerza y los amenazó, hablándoles en inglés y algunas palabras en español, con traer a la policía si seguían "causando disturbios". Quizá para él dicha situación representaba el inicio de una pelea o simplemente fue el pretexto para ejercer su poder o controlar la situación y así evitar conflictos; sin embargo, desde mi observación, el empleado no entendió que ésa es la manera en que muchos mexicanos, en situaciones similares, se relacionan y expresan una serie de sentimientos que en otros momentos no suelen hacer, por lo que tal comportamiento distaba mucho de ser un hecho violento.

A esas imágenes se le sumaron otras más que ya había presenciado desde mis primeros acercamientos al tema de la migración agrícola en Canadá, lo que me llevó a orientar mi mirada hacia las relaciones interculturales y las representaciones sociales que traen a cuestas los migrantes. Me percaté de que ni en esos espacios de "diversión" los jornaleros y jornaleras pueden relacionarse libremente sin ningún temor a ser estigmatizados y, en el peor de los casos, deportados.

Como resultado de esta reflexión, decidí adentrarme en la bibliografía que había abordado el tema de los trabajadores agrícolas en Canadá, con la finalidad de identificar los trabajos que se habían enfocado en las relaciones entre migrantes y sociedad receptora. Los hallazgos de los investigadores coincidieron en su mayoría con lo que observé posteriormente. A lo largo de este artículo presento los más significativos.

La revisión de este material me dio las bases para profundizar con mayor detalle, por lo que me enfoqué en analizar de acuerdo con qué esquemas de percepción, pensamiento y acción se construyen las relaciones entre los canadienses y los migrantes "temporales", planteándome los siguientes objetivos: conocer las representaciones sociales que construyen los quebequenses respecto de los migrantes y observar cómo se traducen los contenidos, la organización y la estructura de las representaciones en las prácticas culturales de los canadienses hacia los jornaleros. Cabe mencionar que en esta investigación no consideré como sujetos de estudio a las mujeres debido a que en Saint-Rémi, hasta el 2011, año en que terminé mi trabajo de campo, no se contaba con su participación en el marco del PTAT.

Para dar respuesta a los planteamientos, mi investigación tendría que fundamentarse en el estudio de la cultura, particularmente de las representaciones sociales que se erigen en la intersubjetividad. La teoría de las representaciones sociales propuesta por Moscovici (1979) ha sido empleada para explicar qué es lo que une a la gente en un grupo o en una sociedad y la hace actuar, de manera individual o conjunta, de una u otra manera. Es una teoría que nos permite explicar, desde la antropología, cómo se construyen y actualizan las identidades colectivas, pero también los estereotipos y prejuicios que guían y son soporte de la acción. 
La metodología que utilicé en esta investigación tiene sus vías principales en la observación directa y participante. La finalidad es elaborar una etnografía que capte el discurso social, más allá de los aspectos meramente formales y declarativos; una estrategia para conseguirlo fue incursionar en los campos agrícolas, espacios habitacionales, centros comerciales y recreativos, iglesias y en los sitios donde la comunidad latinoamericana, ya residente, tiene presencia, y en donde sólo conviven los quebequenses. La otra vía se deriva de la aplicación de instrumentos, como la entrevista semiestructurada dirigida, la escala de valores y la captura de palabras a través de la asociación libre, que nos permiten captar el dominio de lo preinterpretado, la "doxa", y cuyas respuestas nos dan la posibilidad de acceder a las subjetividades. Asimismo, recopilé información relacionada con los jornaleros publicada en los diarios de circulación local. Lo anterior me dio la oportunidad de tener una visión holística sobre su presencia en la localidad.

Para llevar a cabo esta investigación acudí a Saint-Rémi, Quebec, sitio que consideré ideal debido a varias razones que cito enseguida. Quebec es la tercera provincia con mayor demanda de mano de obra extranjera (con un 18 por ciento), precedida por la Columbia Británica (el 24.3 por ciento) y Ontario (el 35.3 por ciento) (cIC, 2011: 75) y concentra el mayor número de trabajadores "temporales" guatemaltecos que laboran bajo el Proyecto piloto, lo que a partir de 2003, de acuerdo con datos de la Dirección de Movilidad Laboral y la Fundación de Empresas de Reclutamiento de Mano de obra agrícola Extranjera (Ferme), produjo menor crecimiento en la demanda de mexicanos (Díaz, 2013: 97). Saint-Rémi, siendo la expresión más representativa de la agricultura quebequense, tiene una alta demanda de trabajadores y un gran desarrollo en su industria agrícola, lo que ha impactado en su estructura sociocultural y económica.

Aunado a lo anterior, a pesar de que Quebec ha sido receptor durante más de veinte años de jornaleros bajo el PTAT y, desde hace ya una década, del Proyecto piloto, hasta hoy no existe ningún estudio que haya examinado a profundidad los vínculos entre los trabajadores agrícolas y la comunidad receptora; sin embargo, cabe mencionar los trabajos de Karen Bronsard (2007), quien centró su estudio en tres regiones: La Montérrégie, Lanaudière y la Capitale-Nationale y nos presenta, muy vagamente, que la percepción de los empleadores sobre los trabajadores mexicanos es positiva y buena, mientras que la de los empleados respecto de los patrones es de confianza, respeto y amistad.

Por su parte, el trabajo de Valarezo (2007), quien se limitó a Saint-Rémi, destaca el aislamiento social, geográfico y la falta de apoyo en el espacio en el que los trabajadores agrícolas se desenvuelven, así como la vulnerabilidad que enfrentan y la modificación de las dinámicas económicas, sociales y culturales durante el otoño e invierno en la comunidad. 
En términos generales, la investigación realizada por instancias quebequenses, como la Universidad de Montreal, el Centro Metrópolis de Quebec, la Universidad de Quebec, el Instituto Nacional de la Investigación Científica (INRS, por sus siglas en francés), respecto de la migración agrícola "temporal", es incipiente.

El trabajo de campo lo llevé a cabo en tres etapas definidas básicamente por dos variables relacionadas: el clima frío quebequense y el desplazamiento de los jornaleros entre sus comunidades de origen y Canadá. La primera se hizo de octubre de 2010 a enero de 2011 en Saint-Rémi, la segunda comprendió enero y febrero de 2011 en México (Puebla, Tlaxcala, Morelos y el Estado de México), en tanto que la tercera fue de marzo a noviembre de 2011 en Saint-Rémi. Me entrevisté con cincuenta y un personas, treinta y tres de las cuales nacieron en Quebec y el resto en diferentes países: Francia, Costa de Marfil, México, Guatemala, El Salvador, Nicaragua, Costa Rica, Panamá y Colombia. Las entrevistas tuvieron lugar en casas, sitios de empleo o en algún restaurante. Cabe aclarar que los instrumentos que se aplicaron a los francófonos fueron elaborados en su lengua materna, posteriormente escuché todo el material grabado varias veces y traduje al español únicamente los extractos que consideré relevantes para mi investigación.

Entre los temas que consideré más importantes del material analizado destacan los siguientes: cambios en la comunidad, fiesta de culturas, descripción de Quebec a partir de Ontario, comparación entre México y Quebec (dinero, cultura, trabajo, familia, pobreza frente a riqueza, estrés frente a tranquilidad), descripción de los mexicanos, guatemaltecos y quebequenses, jornaleros vistos como objetos, cambios en la producción agrícola (clima, tecnología, temporalidad), relación de los jornaleros con los patrones, discurso de bienvenida para los migrantes agrícolas, proteccionismo de los empleadores, prejuicios, racismo, exclusión y discriminación de los migrantes, falta de integración entre las nuevas familias de la comunidad y las fundadoras y la humanización de los trabajadores.

Con toda la información recabada y a manera de síntesis, decidí crear el siguiente esquema que sirve para iniciar la explicación de las representaciones sociales que tienen los quebequenses que habitan en Saint-Rémi. Cabe mencionar que durante la observación participante me percaté de que las representaciones se vinculaban con los grupos de pertenencia, por lo que decidí incluir en este artículo a dos grupos: quebequenses de nacimiento y quebequenses originarios de Latinoamérica, ya que "para entender y extender el alcance de cualquier estructura representacional, es necesario tener en cuenta todo el sistema de relaciones sociales en el cual se construye, es decir, en el escenario natural de la vida misma, que es la vida cotidiana como sistema" (Martín, 2003: 178-179). 


\section{Esquema 1}

LAS REPRESENTACIONES SOCIALES QUE TIENEN LOS QUEBEQUENSES

EN EL ESPACIO RURAL Y URBANO DE SAINT-RÉMI

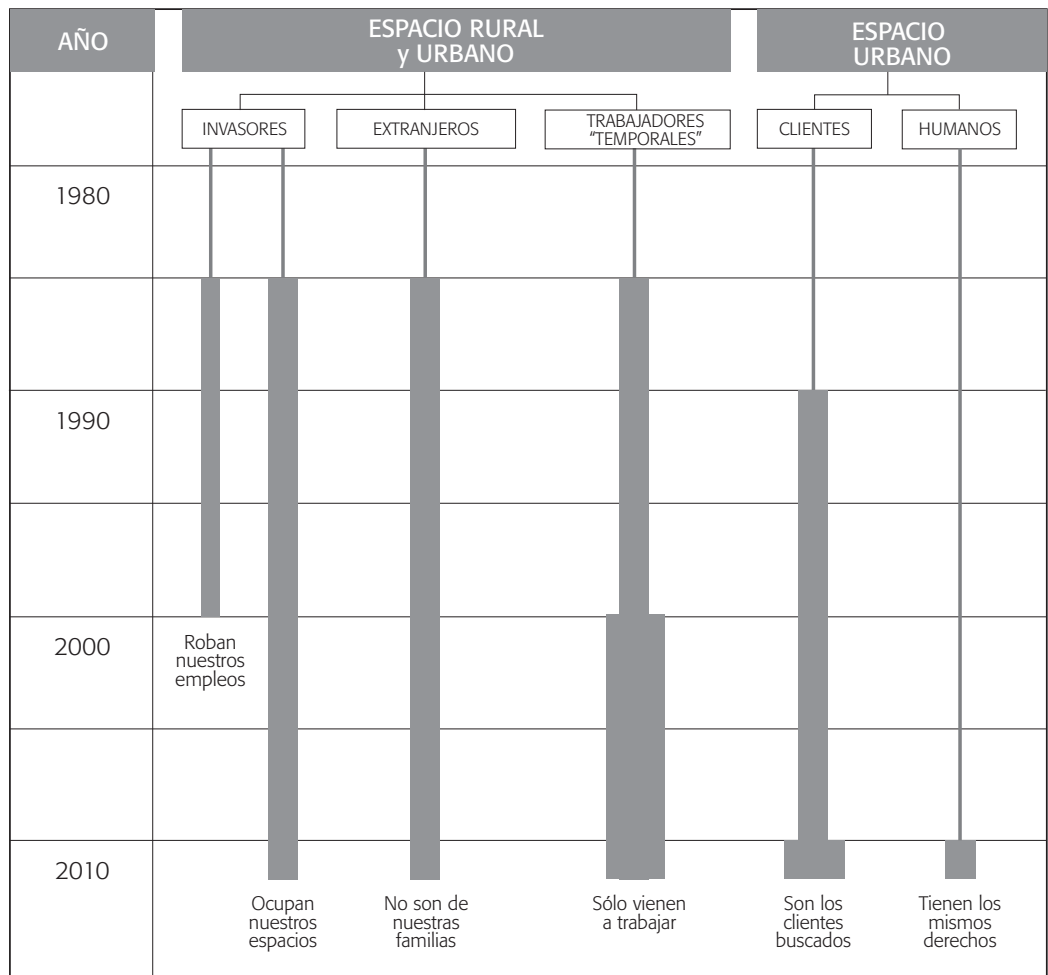

Fuente: Elaboración propia.

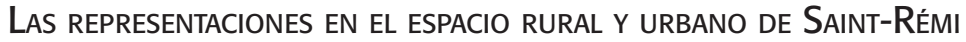

Poco después de haberme instalado en Saint-Rémi, observé que el uso del espacio y el "manejo" del tiempo eran elementos que tendría que observar constantemente, ya que el sentido común me sugería que iban a ser importantes en el proceso de construcción de la representación social. El espacio lo entiendo como

un testimonio: atestigua sobre un momento de un modo de producción por la memoria del espacio construido de las cosas fijadas en el paisaje creado... es una forma durable que no se deshace paralelamente al cambio de los procesos: al contrario, algunos procesos se adaptan a las formas preexistentes mientras que otros crean nuevas formas para insertarse en ellas (Santos, 1990: 154). 
En este sentido, el que los jornaleros estén presentes en los mismos espacios y momentos en que los quebequenses quieren hacer uso de éstos crea un conflicto debido a que son violentadas las estructuras mentales, al evidenciarse las diferencias culturales, las jerarquías sociales y las cuestiones raciales. Esto se manifiesta en la vida cotidiana de diferentes maneras. Cecil y Ebanks (1991) encontraron hostilidad e indiferencia hacia los trabajadores, mientras que Colby (1997), Basok $(2002 ; 2004)$ y Smart (1997) identificaron racismo y discriminación (Preibisch 2007:104).

A través del trabajo de campo descubrí que en Saint-Rémi existe una división física e imaginaria entre el espacio rural y el urbano, la cual influye en la manera en que se establecen las relaciones sociales y se construyen las representaciones de la otredad. Por ejemplo, en la parte urbana, la edificación entre una casa y otra es más próxima. En los últimos años se han construido casas dúplex y pequeños edificios de departamentos que habitan parejas jóvenes originarias de dicho lugar o personas provenientes de otras latitudes de Quebec; de hecho, el incremento demográfico en Saint-Rémi se concentra en el área urbana. Esta reciente reurbanización aumenta las posibilidades de que los vecinos establezcan algún tipo de contacto, mientras que en la zona rural las casas están mucho más separadas y las probabilidades de compartir los espacios públicos son mucho menores.

\section{LOS QUEBEQUENSES Y SUS REPRESENTACIONES EN EL ÁREA RURAL DE SAINT-RÉMI}

De acuerdo con el Censo de Agricultura (Government of Canada, Statistics Canada, 2011), Saint-Rémi posee una superficie inminentemente ocupada por actividades relacionadas con la agricultura y, por ende, habitada por personas que, desde sus antepasados, se dedican al cultivo de la tierra. Este hecho influirá en la representación, ya que fueron sólo algunas de estas familias las que solicitaron la presencia de hombres de otras nacionalidades para laborar en sus tierras; sin embargo, en los años ochenta, con la llegada de los mexicanos a las granjas, también hubo descontento entre otros habitantes que vivían en la zona rural, sobre todo entre los agricultores que no eran propietarios de grandes extensiones de tierra o las familias que se dedicaban a la agricultura, pero no contrataban gente del PTAT. Para estos últimos, la representación estaba estrechamente asociada con la de invasores-ladrones de empleos, ya que no todos querían tener gente que no fuera quebequense en su tierra. Si bien en los campos ya habían trabajado personas de diferentes culturas, sobre todo de origen asiático y caribeño que viajaban desde Montreal durante el verano y que en su mayoría gozaban de los derechos que les otorgaba el ser ciudadanos canadienses, hasta 
esos momentos, nunca antes había habido trabajadores "temporales" no ciudadanos canadienses, lo que le daba una dimensión diferente de la representación.

\section{DE INVASORES-LADRONES DE EMPLEO A TRABAJADORES "TEMPORALES"}

Los primeros en contratar gente con permisos de trabajo "temporales" fueron los grandes empresarios de la zona. Estas familias fueron punta de lanza en el surgimiento de la agroindustria entre las más importantes destacan Riendeau, Guinois, Cousineau, Barbeause y Willson. Por su parte, los medianos y pequeños agricultores se unieron a este proyecto debido fundamentalmente a tres factores: incremento en la productividad de las granjas donde ya habían sido empleados hombres mexicanos, aumento en la dificultad para encontrar personal quebequense dispuesto a trabajar en la agricultura y para mantenerlo disponible cuando la producción lo demandara, y sugerencia por parte de la Unión de Productores Agrícolas (UPA) y de la Fundación de Empresas de Reclutamiento de Mano de obra agrícola Extranjera (Ferme, ambas por sus siglas en francés), de contratar personal mexicano y, años más tarde, guatemalteco.

Para los agricultores, dentro de este esquema de contratación, la problemática de la escasez de mano de obra estaba solucionada; sin embargo, inmediatamente se evidenciaron diferencias culturales entre los grupos que ahí convergían, algunas de ellas provocaron malestares y otras fueron capitalizadas por los mismos empresarios. Por ejemplo, en la comunidad se tiene la creencia de que los mexicanos se adaptan fácilmente al clima cálido, por ser originarios del trópico, lo que los hace muy resistentes al trabajo.

Otra de sus cualidades es su entrega y capacidad de sacrificio por la familia, lo que se transforma en una dedicación ferviente al trabajo para poder enviar más dinero a sus lugares de origen. De igual manera, los empresarios aprecian que sean obedientes y no problemáticos, pues esto beneficia la productividad. Sobre este discurso de la mexicanidad y el reforzamiento de ciertos estereotipos, Binford (2009) argumenta que éstos benefician a los productores.

Por otro lado, los malestares para los oriundos de Saint-Rémi estaban vinculados con las actitudes, creencias y hábitos de los mexicanos. Estas incomodidades iban desde los olores de lo que cocinaban, la forma en que se conglomeraban en la calle, la manera en que reían, lo "ruidosos" que podían llegar a ser, el desorden que generaban en los supermercados, en fin, toda una serie de prácticas culturales vinculadas con la identidad de los jornaleros. En este sentido, podemos hablar de una lucha simbólica en la que se estigmatiza la identidad dominada por "ideologías discriminatorias 
como el racismo, el aristocratismo, el elitismo clasista o la conciencia de la superioridad imperial" (Giménez, 2009: 58). Ejemplos de estas situaciones las encontramos muy bien documentadas en La miseria del mundo (Bourdieu, 2010).

Las molestias han impactado en la población local desde que comenzaron a llegar los mexicanos. En un inicio, éstas eran muy esporádicas, pero con la contratación masiva de jornaleros se ha vuelto más frecuentes. Para contrarrestar los problemas, los empleadores crearon mecanismos que controlaran lo más posible la vida de los migrantes, tanto dentro como fuera del tiempo y área de trabajo. Siguiendo a Foucault, observamos que

a medida que el aparato de producción se va haciendo más importante y más complejo, a medida que aumentan el número de los obreros y la división del trabajo, las tareas de control se hacen más necesarias y más difíciles. Vigilar pasa a ser entonces una función definida, pero que debe formar parte integrante del proceso de producción; debe acompañarlo en toda su duración (Foucault, 2002: 179).

La disposición más efectiva de control consiste en que los jornaleros habiten en el mismo lugar de trabajo, es decir, en la granja del empleador. Primeramente, que los migrantes vivan en el mismo espacio donde se emplean hace que su mano de obra esté disponible las 24 horas del día, lo que garantiza su participación a tiempo en el proceso productivo (regulado por un mercado global), recordemos que estamos hablando no de la agricultura tradicional, sino de procesos agroindustriales. En segundo término, que los jornaleros estén cautivos en el espacio laboral-habitacional dificulta que se involucren con otras personas, lo que, desde el punto de vista de los empresarios, es positivo, ya que no tienen distracciones ni generan problemas en la comunidad.

Finalmente, que las granjas se encuentren alejadas de los centros urbanos, a una distancia que varía entre tres y diez kilómetros, dificulta el acceso de los trabajadores agrícolas a la zona urbana, debido a que regularmente sólo cuentan con bicicleta y en ocasiones ni siquiera con ésta, lo que los circunscribe a permanecer en la granja bajo la mirada del empleador, su familia y los capataces. Cabe resaltar que para el papel de capataz suele ser designado un hombre de origen mexicano, con un estatus de residente o bien de "trabajador temporal"; en este último caso, la jerarquía no suele tener una remuneración económica extra, sino más bien de tipo simbólica, traducible en favores para el capataz, siendo la seguridad de trabajo para el año venidero la más importante para ambos actores.

En este ejercicio del poder, algunos empleadores prohíben las visitas de amigos, estudiantes, vendedores, personas de organizaciones civiles y gente del sindicato, para ello han instalado circuitos de cámaras que cubren la entrada de las casas don- 
de viven los migrantes o ciertos espacios laborales para vigilar quiénes llegan, quiénes salen y qué hacen. Aunado a lo anterior, hay reglamentos que suelen estar pegados en el interior de las viviendas, que prohíben la entrada de visitas, asimismo, algunos patrones tienen la costumbre de entrar de improviso para supervisarlos, de acuerdo con la premisa de que tienen todo el derecho de hacerlo porque las casas son de su propiedad. Estrategias más drásticas llegan al grado de atentar contra la libertad de los migrantes al privarlos del transporte y medios de comunicación. Ésta es una conducta evidentemente violenta. Es el ejercicio del poder y la violencia emocional hacia la víctima cautiva. Es interesante observar cómo estas estrategias que utilizan algunos granjeros coinciden con las dinámicas de los hombres que abusan de las mujeres o que están involucrados en la trata de personas: primeramente limitan los contactos de la víctima con el exterior, es decir, "la dislocan", posteriormente la víctima pierde todo contacto con sus redes y queda a expensas de su victimario.

Lo anterior es una manera de ilustrar cómo los jornaleros se encuentran en un riguroso contexto disciplinar, cuyo objetivo fundamental es generar una relación de "docilidad-utilidad", "la cual incrementa las fuerzas del cuerpo (en términos económicos de utilidad) y disminuye esas mismas fuerzas (en términos políticos de obediencia)" (Foucault, 2002: 141-142).

Estas situaciones crean una atmósfera de aislamiento y la vigilancia se transforma en un operador económico decisivo, ya que representa una parte del aparato de producción, y a su vez un engranaje del poder disciplinario (Foucault, 2002: 180).

A su vez, algunas de las estrategias de control empleadas sobre los jornaleros pueden influir en la construcción del género. El siguiente testimonio de una empresaria quebequense evidencia cómo surgen reajustes en las relaciones de género durante el proceso migratorio: “Los patrones han advertido a los trabajadores, aquí no es México, nosotros no hacemos eso con las mujeres (se refiere a mirarlas de 'manera libidinosa'), no las vemos como si fueran un pedazo de carne". "Yo hago eso con mis trabajadores cuando llegan aquí, les digo aquí no se hace eso, puede ser allá, pero aquí es otra cosa. Ustedes deben adaptarse a como es Quebec. Ahora los mexicanos son muy respetuosos, no como antes". Así, "la migración pone en tensión las normas, creencias y representaciones colectivas de lo que socialmente se considera como el comportamiento y los atributos "legítimos" de lo masculino y femenino" (Barrera y Oehmichen, 2000).

Los empleadores no sólo controlan el tiempo de trabajo de los migrantes, sino también el de descanso, basándose en una moral puritana, pero también en la disciplina del panóptico al que se refiere Foucault, entendida ésta como "un modelo generalizable de funcionamiento; una manera de definir las relaciones del poder con la vida cotidiana de los hombres" (Foucault, 2002: 208). 
Cabe mencionar que existen empleadores que son más flexibles en las medidas de control, algunos de ellos les proporcionan transporte para que salgan por lo menos algunas horas a hacer sus compras y enviar sus remesas, esto regularmente es el jueves o el viernes. Pero hay jornaleros que no se conforman con ese tiempo fuera de la granja, ya que no soportan estar encerrados, así que, al finalizar su jornada laboral del sábado o del domingo, toman su bicicleta o llaman un taxi y se van al centro para distraerse. Es importante aclarar que no todas las medidas de control utilizadas por los empleadores son tan violentas o evidentes, existen otras más sutiles, como son los consejos y llamadas de atención en una tesitura más paternalista que generan lealtad de los trabajadores hacia sus patrones, lo que, entre otras cosas, los hace no abandonar las granjas y asumir un papel de subordinación. Esta situación ya había sido identificado por Basok (2000).

Por otro lado, algunos empleadores, durante el invierno, deciden viajar a algún sitio de playa en México y visitar a los jornaleros en sus comunidades de origen, lo que puede llegar a significar un ejercicio de control al conocer a la familia y a las comunidades de los migrantes.

En este contexto de paternalismo, algunos patrones han sido elegidos como padrinos de los hijos de los migrantes. Regularmente este padrinazgo no está vinculado con las celebraciones que impliquen los principales sacramentos católicos, sino más bien con eventos como el término del ciclo escolar. De acuerdo con Agnès Fine (1998), podríamos decir que se trata de una especie de "parentesco elegido" que también puede ser "temporal".

Elementos como el control, el poder y la vigilancia forman parte de la estructura de la representación que paulatinamente los transformó de invasores-ladrones de empleo, a "trabajadores temporales". De acuerdo con Himmelweit y Gaskell (1990), podemos hablar de que se trata de una nueva representación, ya que el comportamiento y pensamiento colectivo de la mayoría de los agricultores se tornó diferente de sus sistemas representacionales anteriores. En este sentido, las familias empresarias con mayor poder en la región tuvieron un papel fundamental en la transformación de la representación debido, entre otras cosas, a su influencia en los pequeños productores y en la población en general para que aceptaran la llegada de trabajadores "temporales". En el caso de la provincia de Quebec, en el año 2000, 130 granjas empleaban trabajadores agrícolas extranjeros y diez años después el numero se incrementó a 591 (Ferme, 2010), los trabajadores agrícolas ya no iban a robar empleos, sino más bien a ocupar plazas que estaban vacantes y que era urgente cubrir para la supervivencia de la actividad agrícola.

En esta nueva representación, lo que predomina es el orden económico, de esta manera, los jornaleros se convirtieron en una importante pieza del mecanismo pro- 
ductivo. Así, los patrones consideran que los migrantes son parte de los medios de producción y que ellos son sus propietarios. Al entrevistar a los empresarios, es muy frecuente encontrar en su discurso el uso de pronombres posesivos al momento de referirse a los hombres que laboran en sus granjas.

La representación como trabajadores temporales perdura hasta el momento y lejos de desvanecerse se consolida aún más; esto se debe, entre otras cosas, a la manera como son diseñados y aplicados los programas temporales. Desde el mecanismo de reclutamiento de los migrantes se delinea cuál será el rumbo de la representación social y las relaciones que de éste se deriven. Siguiendo a Binford (2006), ubicamos estas relaciones en campos de poder dirigidos por las demandas laborales de los empresarios canadienses.

La mercantilización de la fuerza de trabajo es la columna vertebral de la estructura de esta representación. Bajo esta mirada se percibe a los migrantes como mercancías. Es común escuchar entre los habitantes de Saint-Rémi que es un gusto de los migrantes tener jornadas laborales largas y extenuantes, ya que los mexicanos y guatemaltecos quieren mandar mucho dinero a sus familias, asimismo, evidencian que los jornaleros están acostumbrados a realizar trabajos en temperaturas más elevadas, ya que provienen de sitios bastante calurosos, por lo que en ocasiones cuando durante el verano las temperaturas rebasan $\operatorname{los} 30^{\circ} \mathrm{C}$ no es menester hacer pausas en la jornada laboral o proporcionarles bebidas refrescantes para evitar golpes de calor, debido a la buena resistencia que tienen los mexicanos y guatemaltecos. En este sentido, no tenemos que olvidar que una de las funciones de la representación es la orientación de las conductas y las relaciones sociales (Jodelet, 1986: 486).

Los argumentos de los quebequenses y, en general de los canadienses, concluyen que la situación de los jornaleros en Canadá es muy buena consecuencia y como sus percepciones económicas son más altas que en sus países de origen y las condiciones de las viviendas, mucho mejores. El análisis que las comunidades de acogida hacen siempre comprende sólo el nivel económico. Empero, nunca argumentan que se paga un buen salario o que el trabajo agrícola ofrezca buenas condiciones laborales para ellos mismos. Es claro que este discurso se construye desde una postura colonialista, en el que las condiciones más difíciles, según ellos, de un país desarrollado como Canadá, no son en lo absoluto comparables con las que pudieran tener los jornaleros en sus países de origen.

Por supuesto que las situaciones socioculturales y políticas que los migrantes tienen que enfrentar en Canadá no son consideradas por los quebequenses como algo sustancial en la vida de los mexicanos y guatemaltecos, pues, según su propio esquema, los jornaleros sólo están interesados en ganar dólares. Aunado a esto, está la representación de que los trabajadores "temporales" no tienen por qué tener los 
mismos derechos que los ciudadanos canadienses, pues ellos sólo están de paso. Esta representación pone en vulnerabilidad a los trabajadores agrícolas, tanto en los espacios de trabajo, como en los que no lo son y, con base en el discurso de que no son oriundos de ese lugar, las acciones se justifican.

Estos procesos de exclusión no sólo se dan a nivel de la comunidad, sino que el mismo Estado canadiense los ejerce, y qué mayor prueba que las restricciones a los trabajadores agrícolas para poder inmigrar a Canadá, junto con otra serie de políticas restrictivas interesantes de analizar (Satzewich, 1991; Sharma, 2006). En su momento, Preibisch (2003) señaló que la Provincial Occupational Health and Safety Act y la restricción de formar sindicatos eran mecanismos de exclusión; sin embargo, gracias a la suma de fuerzas por parte de académicos, organizaciones no gubernamentales, y el propio sindicato, los trabajadores en Ontario, a partir del 2006, fueron incorporados al Acta de seguridad y salud ocupacional en Ontario y algunos trabajadores en ciertas granjas en Columbia Británica, Quebec y Manitoba ya tienen la libertad de sindicalizarse. Desde la postura de Preibisch, esto es sin duda un elemento que influirá en las relaciones sociales entre trabajadores migrantes y canadienses.

Queda claro que la representación se relaciona únicamente con la cuestión laboral, así que cuando los jornaleros buscan desarrollarse en otras actividades fuera de este ámbito es motivo de sorpresa entre un sector de la población, debido a que para ellos el único objetivo que deben cumplir los migrantes durante su estancia en Canadá es trabajar.

\section{LAS REPRESENTACIONES QUE TIENEN LOS QUEBEQUENSES EN EL CONTEXTO URBANO}

Me percaté también de que en el área urbana de Saint-Rémi existen sitios donde los jornaleros acuden sistemáticamente y otros en los que nunca se aparecen. Los trabajadores agrícolas frecuentan los siguientes lugares: campos deportivos, específicamente las canchas de futbol, principales calles de la ciudad, pequeños comercios y supermercados, restaurantes, bancos, bares, la iglesia, la clínica y el centro de apoyo. Mientras que la biblioteca, el escenario, el centro comunitario, las organizaciones civiles, la radio comunitaria, el gimnasio, ciertos comercios y otras calles residenciales son áreas donde prácticamente nunca se ve a los jornaleros, tampoco a los inmigrantes latinoamericanos, ya que sólo se ve "personas blancas". Estamos hablando de que en ciertos espacios se crean procesos de exclusión, los cuales Preibisch (2004) ya había identificado en Ontario, atribuyéndolo a la ciudadanía, la diferencia social y el control que se ejerce en el PTAT a través de las políticas de reclutamiento, retención y repatriación, como elementos fundamentales en su formación. 
En Saint-Rémi, la ruta que siguen los migrantes en la zona urbana está condicionada por la ubicación de los sitios comerciales que ellos frecuentan, sólo durante el verano se amplía al incorporar el área donde se encuentran las canchas de futbol y, cuando hay ventas de garaje, los migrantes circulan en bicicleta en las zonas residenciales a las que en otros momentos no tendrían acceso. La apertura de los límites territoriales está establecida por los quebequenses que desean vender sus cosas usadas. Cabe aclarar que no se trata de una barrera materializada con ninguna cerca o señal de no pasar, sino de una psicológica que distingue perfectamente que la zona residencial no es de trabajo ni de consumo para los jornaleros, por lo que no tienen por qué estar ahí.

Se debe resaltar que la presencia de los jornaleros en los lugares mencionados depende de la temporada del año, si bien su estancia en Saint-Rémi ya abarca todo el año, debido a que algunos de los guatemaltecos laboran en el invierno, también es un hecho que de junio a septiembre la concentración es mucho mayor. En octubre, la cosecha de la mayoría de frutas y vegetales ha terminado, las temperaturas empiezan a descender y los jornaleros se preparan para partir a sus hogares.

La presencia de los jornaleros en los espacios señalados es el elemento primario que los quebequenses utilizan al momento de construir la representación. "Invasión" es el concepto central y está relacionado con los espacios, los empleos y con lo extranjero.

La cantidad de migrantes en los campos de cultivo ha dejado de ser una cifra expresada en cientos para convertirse en miles, lo que desde el punto de vista de los quebequenses que habitan en las áreas urbanas representa una invasión. Actualmente, los jornaleros ya no pasan inadvertidos, su numerosidad los vuelve visibles, sobre todo en las tiendas donde compran sus despensas, en los bancos donde cobran sus salarios y, finalmente, en las mismas calles donde transitan.

\section{LA REPRESENTACIÓN COMO "INVASORES DEL ESPACIO URBANO"}

La representación que los quebequenses se hacen de los jornaleros como "invasores del espacio" se ejemplifica de distintas maneras. La más evidente es la del supermercado IGA y los bancos. Todos saben que los jueves es el día en que los migrantes hacen sus compras, ya que los granjeros les autorizan que vayan a surtirse de víveres, por lo que, a partir de las cinco de la tarde, tiendas, bancos, restaurantes y algunas calles se ven concurridas por migrantes, lo que para los quebequenses ha representado una reorganización de sus actividades para no asistir a estos sitios y evitar, en la medida de lo posible, cruzarse con ellos. 
Si bien, la presencia de los jornaleros ha incrementado las ganancias de los dueños de los negocios, algunos comerciantes, sobre todo quebequenses, no están dispuestos a perder a sus clientes canadienses ni a tener problemas por "gente que sólo viene temporalmente". Justamente durante mi estancia en Saint-Rémi, los problemas vinculados con "el exceso" de mexicanos y guatemaltecos en la tienda y la "falta de alimentos, porque ellos se llevan todo" (citas de mi diario de campo) habían propiciado que se creara un supermercado más grande.

En cuanto a los bancos, éstos han asignado una sola caja para los mexicanos y el resto para los canadienses para que no hagan fila. Esta última acción es un acto evidente de discriminación, pero para los empleados del banco sólo representa una medida práctica. Su argumento es que sólo una cajera sabe hablar español. Cabe aclarar que los migrantes que asisten a los bancos siempre realizan el mismo tipo de movimiento, cobrar el cheque que se les paga para lo cual no es necesario ser hispanohablante.

Por medio de las actitudes, del lenguaje no verbal y de las entrevistas se evidencia que la figura de los migrantes choca con el tradicional uso de servicios y espacios al que los quebequenses estaban acostumbrados. Si bien los trabajadores agrícolas tienen más de dos décadas en Quebec, aún hay gente que no termina de acostumbrarse, y no me refiero a las largas filas en los establecimientos, sino a su presencia en la comunidad.

\section{INVASORES-LADRONES DE EMPLEO}

Otro de los campos con el cual la representación social está estrechamente vinculada es la actividad laboral. Pese a que todos los jornaleros que llegaron a la región a través del PTAT trabajaban solamente en la agricultura, la relación como invasores-ladrones de empleo fue expresada tanto por personas que vivían en la zona rural como en la urbana, cuyos perfiles laborales eran diversos: desde pequeños comerciantes hasta agricultores, tanto hombres como mujeres, todos originarios de la comunidad.

La representación se atribuye a que los mexicanos y guatemaltecos llegan para "robar" el empleo de "nuestra gente", de "nosotros los quebequenses". Algunas de las siguientes frases ilustran lo anterior: "Yo pensé que nos venían a robar los trabajos", "ellos toman el trabajo de los quebequenses", "nos sentimos invadidos".

A esta representación de invasión, se suman atributos adjudicados a los mexicanos que, en su momento, de acuerdo con los habitantes de Saint-Rémi, provocaron una situación difícil de enfrentar, ya que no entendían muchas de sus formas de ser, les parecían extrañas y, en ocasiones, molestas. Entre estas "peculiaridades" mencionaron las siguientes: el valor para dejar a sus familias, la gran resistencia que tienen 
para el trabajo, comen los elotes a la parrilla, comen mucho picante, miran a las mujeres como si fueran un pedazo de carne, son seductores, hacen grandes fiestas y traen muchas bebidas, van mucho a las ventas de garaje, andan en bicicleta en grupo y utilizan toda la calle, orinan sobre los árboles, se reúnen en la calle y ocupan toda la banqueta, ríen y toman cerveza.

Desde la óptica de los quebequenses, las cosas se han relajado, esto lo expresan en su discurso, en el que reflejan mayor apertura. Es claro cómo los quebequenses hablan de dos momentos de la representación: la primera está más vinculada con la invasión y el rechazo hacia los mexicanos por sus diferencias; la segunda, más con la costumbre y el hábito a esta situación.

Lo anterior nos habla de una transformación en la representación, de una paulatina pérdida de fuerza de la representación de invasores-ladrones de empleos para adquirir matices distintos. La transformación se debe a varios factores. Los habitantes de Saint-Rémi, tanto en el área urbana como en la rural, se dan cuenta de las repercusiones económicas positivas que han traído la presencia de los jornaleros, tanto en el sector primario como terciario. Otro de los factores que influye en este viraje es que la actividad agrícola ha pasado a formar parte de la lista de empleos mal remunerados que los quebequenses no quieren realizar, por tratarse de un trabajo de mucho sacrificio, baja calificación y jerarquía, o bien porque buscan mejores salarios o la manutención por parte del gobierno a través de la ayuda social.

Si bien la agricultura en Quebec aún cuenta con mano de obra local, ésta representa un menor porcentaje en comparación con la de los trabajadores extranjeros "temporales". Durante mi trabajo de campo observé que los quebequenses suelen desarrollar actividades agrícolas que demandan menos esfuerzo físico y su mano de obra es mayormente utilizada para cosechar manzana y fresa, en estos cultivos no están obligados a un horario y la paga se da al finalizar la jornada. Estamos hablando de trabajos "por debajo de la mesa".

Otro elemento que también ha influido en el cambio de la representación es que ahora la gente de Saint-Rémi tiene más oportunidad de viajar, sobre todo a los sitios de playa de México y el Caribe, lo que posibilita descubrir otros elementos de la situación socioeconómica y cultural de los mexicanos y tener la posibilidad de entablar relaciones en otro contexto. Finalmente, el hecho de que los habitantes de Saint-Rémi en la actualidad tengan más oportunidades que antes de formarse a nivel medio superior o superior en ciudades como Montreal, Sherbrooke, Laval o el mismo Quebec, abre una veta hacia el reconocimiento de los migrantes "temporales" desde perspectivas más humanistas.

Si bien es cierto que la tensión entre los grupos que conviven en Saint-Rémi ha disminuido y que paulatinamente el grupo receptor ha entendido que ellos ya no 
estaban interesados en hacer el trabajo de la agricultura, aunque éste tenía que llevarse a cabo para continuar con la producción de frutas y vegetales, y así tener una economía agrícola estable; todavía está latente el rechazo hacia los migrantes y la violación a sus derechos.

Para los quebequenses no es suficiente saber que la agricultura en la provincia necesita de mano de obra extranjera y que los jornaleros no son ladrones de empleos. Algunos de ellos aún conservan una representación negativa. Los nuevos inmigrantes o sus hijos se vuelven conscientes de este hecho y lo critican evidenciándolo en su discurso.

\section{INVASORES-EXTRANJEROS}

Para los quebequenses de Saint-Rémi, lo importante y lo que tiene valor sigue siendo lo local, "lo que es de ahí", lo extranjero continúa representando una invasión. Recordemos que se trata de una sociedad muy conservadora, que hasta apenas hace unas décadas estaba dominada por el clero. Las primeras familias siguen ostentando el poder político, económico y social en la zona. De alguna manera ellas toman las decisiones para determinar quiénes pertenecen al lugar y quiénes son excluidos. Algunos indicios o atributos de identidad para definir quién está incluido y quién no son los siguientes: en primer lugar, lo que cuenta son los apellidos, porque eso es un indicio de pertenencia a las familias que han vivido allí más de un siglo; el segundo es el haber nacido allí, esto les garantiza la pertenencia a la comunidad; el tercero, ser francófono, pero quebequense; el cuarto está vinculado con la raza, reconociendo como su origen racial la "raza blanca" y, finalmente, compartir las mismas prácticas culturales.

Vemos los apellidos de las familias fundadoras de Saint-Rémi no sólo en los nombres de las calles del poblado, sino también entre los políticos, empresarios o bien entre los miembros de los comités que marcan el presente y futuro de Saint-Rémi y, por ende, de la situación de los jornaleros. Ejemplo de éstos son Boyer, Lefrançois, Perras, Riendeau, Robert, Ste-Marie, Yelle, Hartel, Barber, Normandin, Boucher (apellidos tomados de Labergue y Chayney, 1980).

Debido a que el origen de la ciudad se remonta a 1830, el número de las familias se ha incrementado, éstas se han conformado regularmente de la unión entre miembros de las familias originarias de Saint-Rémi y un integrante proveniente de otro lugar de Quebec. A esta elite familiar no pertenecen los sujetos que migraron de distintos países, pese a su origen francófono. Esto muestra la fuerte raíz que dichas familias tienen en Quebec y en particular su comunidad.

Esta especie de proteccionismo ha estado latente en todos los lugares, no sólo se ha circunscrito al medio en el que los migrantes agrícolas se desenvuelven. Hace poco 
más de veinte años se trataba de una situación realmente exacerbada, aún los quebequenses de otra región eran medianamente bienvenidos, aunque no podían ocupar puestos públicos importantes; por ejemplo, sólo hasta el 2009 se eligió, por primera vez, un consejero para el distrito rural, que no era nativo de la comunidad y que tenía pocos años de haber llegado.

Por otro lado, las personas francófonas que no habían nacido en Quebec también eran excluidas y agredidas psicológicamente. Esta problemática tan compleja no sólo se queda en el imaginario de los actores sociales, sino que la representación social es la acción misma. Cito a Abric: “Es una guía para la acción, orienta las acciones y las relaciones sociales. Es un sistema de predecodificación de la realidad, puesto que determina un conjunto de anticipaciones y expectativas"' (2001: 13).

Ante la representación social de invasores que se tiene de los jornaleros, su situación de vulnerabilidad no sólo está presente en la parte laboral; también se expande a otros espacios, permeando todo el contexto social en el que se desenvuelven.

\section{LOS QUEBEQUENSES DE ORIGEN LATINOAMERICANO Y SUS REPRESENTACIONES}

Las áreas donde los latinoamericanos empiezan a ganar terreno están estrechamente vinculadas con los comercios, sobre todo las que ofertan productos mexicanos y guatemaltecos, y el servicio de envío de remesas. De hecho, la idea que tenían los latinoamericanos antes de mudarse a la comunidad era explorar cuáles eran las necesidades de los jornaleros para ofrecérselas. Los nuevos negocios se enfocaron fundamentalmente a la venta de productos comestibles, básicamente mexicanos, a la distribución de tarjetas telefónicas y al servicio de envío de remesas.

Gracias a este grupo de personas, la situación en los últimos años para los mexicanos y guatemaltecos ha mejorado, ya que ahora cuentan con un mayor acceso a servicios de envío de dinero y a productos de los que anteriormente carecían. De acuerdo con las opiniones de los jornaleros, es un alivio saber que pueden contar con el apoyo de personas que hablen su misma lengua y que sean sensibles a su realidad.

\section{LA RePRESENTACIÓN: "El Cliente BusCAdo"}

Cabe aclarar que no sólo los hispanos han procurado llamar la atención de los jornaleros, sino que también los quebequenses han hecho su parte. Por ejemplo, las farmacias, los bancos y los supermercados contratan, durante el verano, gente de Quebec 
que hable español para que atraigan a la clientela hispana. En las tiendas como el IGA hay una sección especial de productos mexicanos, los restaurantes han incluido platillos mexicanos y los videocentros cuentan con una gran variedad de películas con subtítulos en español. Todo esto se circunscribe fundamentalmente al aspecto de intercambio comercial, por lo que el jornalero se ha convertido en "el cliente buscado". Por supuesto que esta representación no es únicamente de los latinoamericanos, los quebequenses que tienen algún negocio que oferta productos o algún servicio a los jornaleros también la comparten.

En este sentido, la representación es positiva, ya que los dueños de los negocios se ven beneficiados económicamente con su presencia. Fuera del ámbito comercial, son pocas las actitudes de aceptación y júbilo que se aprecian en la población receptora por tener como huéspedes a personas de otras culturas; sin embargo, en su discurso oral esto toma otros matices. Generalmente éste tiene la pretensión de mostrar, a través de las palabras, una actitud de bienvenida hacia los migrantes, que en la práctica se reduce a un plano netamente material, representado a través de las cosas e infraestructura que se les oferta a los jornaleros, es decir, que se trata de una relación meramente instrumental.

\section{TRANSFORMACIONES EN LAS REPRESENTACIONES, LA PARTE HUMANA}

Fuera del ámbito de intercambio económico, los habitantes de Saint-Rémi, sobre todo los que nacieron ahí, no han tenido suficientes elementos que los ayuden a ser más sensibles con culturas ajenas a la suya. En la comunidad observamos que la inmigración de personas de otras culturas es muy baja y que históricamente Saint-Rémi ha sido un sitio agrícola familiar, donde se ha producido lo necesario para subsistir. La gente solía vender sus productos en expendios fuera de su casa o a pequeños comercios dentro de la misma región. Esta dinámica en la agricultura consumía la mayor parte de su vida (Labergue y Chayney, 1980), por lo que no estaban acostumbrados a convivir con gente de otras culturas, ya que su trabajo no lo necesitaba. Pese a su cercanía con Montreal, muchos de sus habitantes no la conocían, de hecho, en la actualidad, a muchos les resulta una ciudad desagradable para visitar, debido a que hay bastante ruido, caos vial, peligro y también les parece lejos, según sus propias palabras (notas de mi diario de campo); sin embargo, desde hace un par de décadas esto ha cambiado, la agricultura tradicional se ha convertido en una gran agroindustria, lo que ha impactado en las estructuras sociales y económicas de la comunidad.

Con la llegada de los pocos inmigrantes provenientes de otras culturas, los impactos positivos en la economía de la localidad y el trabajo de los colaboradores de la 
Alianza de Trabajadores Agrícolas (ATA) y de otras personas conscientes de las necesidades de los jornaleros, la representación negativa de los migrantes empieza a transformarse. Si bien, en la actualidad aún no se puede hablar de una comunidad latinoamericana consolidada, ya que los pocos inmigrantes se encuentran en una lucha individualista para posicionarse económicamente en Saint-Rémi, existe la posibilidad de que paulatinamente se generen alianzas que conformen un enclave que apoye a los jornaleros con más efectividad, tal como sucede en Leamington, Simcoe y Niágara.

En el último lustro, se han empezado a observar algunas situaciones que buscan que las personas los vean como seres humanos y no como "máquinas de trabajo", aunque aún no podemos hablar de un movimiento consolidado, conviene mencionar que éste ya ha comenzado. Eventos como las parrilladas en el verano, las comidas en la iglesia después de la misa dominical, algunos paseos anuales por sitios turísticos y las clases de inglés han servido para entablar relaciones entre los jornaleros y algunos miembros de la comunidad canadiense, sustentadas no en factores económicos, sino en otros valores, como el de la solidaridad. En este sentido las organizaciones como la ATA, el grupo Somos Hermanos y la Fraternidad Quebequense Latinoamericana han cumplido un papel determinante en la construcción del proceso de inclusión.

\section{Conclusiones}

Las relaciones que construyen los "saint-rémois" con los guatemaltecos y mexicanos están matizadas por el espacio físico en el que se establecen y, a su vez, se encuentran condicionadas por la estructura de los programas de trabajo "temporales". Así, encontramos que, en la zona agrícola, las relaciones tienen un sentido meramente laboral y se jerarquizan en dos roles: uno ejecutado por el empleador, quien controla, y el otro, por el trabajador, quien en general no tiene la posibilidad de defender sus derechos, asumiendo el papel de subordinado.

Las representaciones sociales en el área agrícola es donde históricamente los empresarios agroindustriales han ejercido mayor influencia en su conformación. Su función es legitimar y justificar en la colectividad la explotación de los jornaleros con distintos argumentos, entre los que destacan los siguientes: el migrante viene a Canadá con la única finalidad de trabajar todo el tiempo, para enviar la mayor cantidad de dinero a su familia; los trabajadores agrícolas, por venir de climas cálidos, son resistentes a las altas temperaturas y están acostumbrados a jornadas laborales fuertes y a condiciones de vida paupérrimas, por lo que cualquier cosa que se les ofrezca en Quebec será mucho mejor que la que tienen en sus países de origen; los migrantes 
"temporales" no desean quedarse en Canadá, porque extrañan a su familia y sus costumbres; los jornaleros son temporales, ellos sólo están aquí parcialmente, por lo que no necesitan de más derechos.

La representación social que tienen los quebequenses de los mexicanos y guatemaltecos como trabajadores "temporales" tiene un valor positivo, sobre todo para los patrones, el cual radica en la amplia flexibilidad de la mano de obra. Para la agroindustria canadiense es fundamental contar con trabajadores disponibles en todo momento por las circunstancias tan cambiantes y extremas del clima, la competitividad a nivel mundial y la plusvalía que producen.

La representación social "trabajadores temporales" es una piedra angular de una política del Estado canadiense en la que se niega rotundamente a los trabajadores agrícolas la posibilidad de inmigrar, colocándolos en un estatus migratorio de "temporal" y, por ende, en una posición de vulnerabilidad que los jornaleros enfrentan día a día durante su estancia en Canadá.

Por otro lado, las representaciones sociales en la parte urbana también se rigen por un principio económico; en este contexto, la representación que tienen de los jornaleros es la de "el cliente buscado". Por un lado, se encuentran los latinoamericanos residentes en Quebec que hacen esfuerzos para atraer a los trabajadores "temporales" a sus negocios y, por el otro, están los quebequenses que también buscan captarlos al modificar los horarios de atención, contratar gente que hable español, e introducir productos y servicios que sean del gusto de ellos.

Ese esfuerzo de "condescendencia" se circunscribe únicamente a las dinámicas comerciales que se desarrollan en un espacio y tiempo determinados, sin que por ello exista un mayor involucramiento entre dichos actores.

Sin embargo, existen personas, sobre todo en la parte urbana, que tienen una representación humanista de los jornaleros. Ellas construyen otro tipo de vínculos que no están fundados en la parte económica, un ejemplo lo encontramos en el personal de la ATA, quienes han construido relaciones en las que la solidaridad es su estructura principal.

Tanto en la zona rural como urbana, la discriminación hacia los jornaleros se hace evidente en ocasiones de manera muy sutil y en otras muy abierta. En el ámbito laboral, los patrones ejercen presión y discriminación en sus prácticas cotidianas, pero a su vez los jornaleros son "recompensados" al final de la temporada con una carta de buen desempeño, que prácticamente les asegura un lugar de trabajo para el año entrante.

La importancia de la historia en el estudio de las representaciones sociales en Saint-Rémi fue fundamental para entender el racismo y la exclusión de los jornaleros. Estos hechos no son situaciones que surgieron con la llegada de los campesinos 
mexicanos ni guatemaltecos, sino que se remonta, de acuerdo con los inmigrantes de otros países, al arribo de cualquier persona ajena a la comunidad. Así, los pocos inmigrantes provenientes de Asia, Europa o África fueron rechazados.

En los años ochenta, con la llegada de los trabajadores agrícolas a la comunidad, los quebequenses vinculaban la representación con "invasores" porque "robaban sus empleos", "ocupaban sus espacios" y "no eran parte de sus familias". Esta representación se ha ido transformando a través del tiempo. En la actualidad, los quebequenses saben que sin estos extranjeros, originarios de otras culturas, la agricultura de Quebec no existiría.

\section{FuENTES}

Abric, J. C.

2001 Prácticas sociales y representaciones, México, Ediciones Coyoacán.

BARRERA, D. y C. OEHMichen

2000 Introducción, en D. Barrera y C. Oehmichen, eds., Migración y relaciones de género en México, México, Gimtrap/IIA, UNAM.

BASOK, T.

2004 "Post-National Citizenship, Social Exclusion, and Migrants' Rights: Mexican Seasonal Workers in Canada", Citizenship Studies, vol. 8, no. 1, pp. 47-64.

2002 Tortillas and Tomatoes: Transmigrant Mexican Harvesters in Canada, Montreal, McGill-Queen's University Press.

2000 "He Came, He Saw, He... Stayed. Guest Worker Programs and the Issue of Non-Return", International Migration, vol. 38, no. 2, pp. 215-238.

BINFORD, L.

2009 "From Fields of Power to Fields of Sweat: The Dual Process of Constructing Temporary Migrant Labour in Mexico and Canada", Third World Quarterly, vol. 30, no. 3, pp. 503-517.

2006 "Campos agrícolas, campos de poder: el Estado mexicano, los granjeros canadienses y los trabajadores temporales mexicanos", Migraciones internacionales, vol. 3, no. 3, pp. 54-80.

Bourdieu, Pierre, ed.

2010 La miseria del mundo, Buenos Aires, FCE. 
BRONSARD, K.

2007 Main-d'oeuvre mexicaine sur les terres agricoles québécoises: entre mythe et réalité, Maître, Université Laval.

CeCIL, R. y E.G. EBANKS

1991 "The Human Condition of West Indian Migrant Labour in Southwestern Ontario", International Migration, vol. 29, no. 3, pp. 389-404.

CIC, CAIC

2011 "Facts and Figures: Immigration Overview. Permanent and Temporary Residents", en <http:/ / www.cic.gc.ca/english/pdf/ research-stats / facts2011.pdf>, consultada el 15 de enero de 2014.

Colby, C.

1997 From Oaxaca to Ontario: Mexican Contract Labor in Canada and the Impact at Home, Davis, Institute of Rural Studies.

DíAz Mendiburo, Aarón

2013 "Las representaciones sociales en el contexto de la migración agrícola 'temporal' en Saint-Rémi, Quebec", México, FFyl, unAm, tesis de doctorado.

FINE, AGNÈs

1998 Adoptions. Ethnologie des parentés choisies, París, MSH.

FoucAult, Michel

2002 Vigilar y castigar, Buenos Aires, Siglo XXI.

Fundación de Empresas de Reclutamiento de Mano de Obra

Agrícola Extranjera (Ferme)

2010 Rapport Annuel, Quebec, Ferme.

GIMÉNEZ, G.

2009 Identidades sociales, México, Conaculta/Instituto Mexiquense de Cultura.

Government of Canada, Statistics Canada

2011 "Census of Agriculture", en <http:/ / www.statcan.gc.ca/ca-ra2011/indexeng.htm>, consultada el 15 de enero de 2014. 
Hennebry, J.

2012 "Permanently Temporary? Agricultural Migrant Workers and Their Integration in Canada", IRPP Study vol. 26.

Himmelweit, H. T. y G. GasKell

1990 Societal Psychology, Londres, Sage.

JODELET, D.

1986 “La representación social: fenómenos, concepto y teoría”, en S. Moscovici, ed., Psicología social II. Pensamiento y vida social. Psicología social y problemas sociales, Barcelona, Paidós.

Labergue, F. y M. Chayney

1980 St-Rémi, 150 ans d'histoire, Quebec, St-Rémi.

Martín, C.

2003 "Crisis y emigración en la subjetividad cubana", Revista Internacional de Psicología Social, vol. 1.

Moscovici, S.

1979 El psicoanálisis, su imagen y su público, Buenos Aires, Huemul.

PREIBISCH, K.

2007 “Globalizing Work, Globalizing Citizenship: Community-Migrant Worker Alliances in Southwestern Ontario", en L. Goldring y S. Krishnamurti, eds., Organizing the Transnational: Labour, Politics, and Social Change, Vancouver, uBc Press.

2004 "Trabajadores migrantes agrícolas procesos de inclusión y exclusión social en el Canadá rural", Antropología, México, INAH.

2003 "Social Relations Practices between Seasonal Agricultural Workers, their Employers and the Residents of Rural Ontario Canada", Ontario, NorthSouth Institute.

SANTOS, M.

1990 Por una geografía nueva, Madrid, Espasa Calpe.

SATZEWICH, V.

1991 Racism and the Incorporation of Foreign Labour: Farm Labour Migration to Canada since 1945, Nueva York, Routledge. 
SHARMA, N.

2006 Home Economics Nationalism and the Making of 'Migrant Workers in Canada, Toronto, University of Toronto.

SMART, J.

1997 "Borrowed Men on Borrowed Time: Globalization, Labour Migration, and Local Economies in Alberta", Canadian Journal of Latin American and Caribbean Studies, vol. 29, nos. 57-58, pp. 203-239.

VALAREZO, G.

2007 "Out of Necessity and into the Fields: Migrant Farmworkers in St. Rémi, Quebec", Quebec, Quebec Master of Arts, Queen's University. 